\begin{tabular}{|c|c|c|}
\hline & 1969 & \\
\hline London, England & Aug. 25-29 & $\begin{array}{l}\text { The Global Circulation of the Atmosphere-Joint Meeting with the Royal Me- } \\
\text { teorological Society }\end{array}$ \\
\hline Virginia Beach, Va. & Sept. 3-5 & Third Conference on Weather Analysis and Forecasting \\
\hline Seattle, Wash. & Sept. $8-10$ & Ninth Conference on Agricultural Meteorology \\
\hline Chicago, Ill. & Oct. $13-17$ & $\begin{array}{l}\text { With American Society of Civil Engineers' Sixth National Meeting on Environ- } \\
\text { mental Engineering }\end{array}$ \\
\hline Ann Arbor, Mich. & Oct. 14-16 & With the Sixth International Symposium on Remote Sensing of Environment \\
\hline Boulder, Colo. & Oct. 15-17 & $\begin{array}{l}\text { Conference on "Plan for U. S. Participation in the Global Atmospheric Research } \\
\text { Program" }\end{array}$ \\
\hline Madison, Wis. & Oct. 21-22 & Symposium on "The Future of the Atmosphere" \\
\hline San Antonio, Tex. & Oct. $27-31$ & With AWRA Fifth American Water Resources Conference \\
\hline Austin, Tex. & Nov. 5-7 & $\begin{array}{l}\text { With the American Society of Civil Engineers Irrigation and Drainage Division } \\
\text { Specialty Conference }\end{array}$ \\
\hline Chicago, Ill. & Nov. 7-8 & Third Conference on Weathercasting (Radio \& TV) \\
\hline Miami, Fla. & Dec. 2-4 & Sixth Technical Conference on Hurricanes \\
\hline \multirow[t]{2}{*}{ Boston, Mass. } & Dec. $26-31$ & $\begin{array}{l}\text { With the American Association for the Advancement of Science; including 50th } \\
\text { annual AMS Business Meeting }\end{array}$ \\
\hline & 1970 & \\
\hline Washington, D. C. & Feb. $11-14$ & AMS Golden Anniversary and U. S. Weather Services Centennial Joint Celebration \\
\hline Boulder, Colo. & March 18-21 & With the IUGG and IAMAP. Symposium on Planetary Boundary Layers. \\
\hline Houston, Tex. & March 23-25 & Conference on the Motion and Dynamics of the Atmosphere \\
\hline Santa Barbara, Calif. & April 6-9 & Second Conference on Weather Modification \\
\hline Washington, D. C. & April 20-24 & With the American Geophysical Union \\
\hline Las Vegas, Nev. & May 4-7 & Fourth Conference on Aerospace Meteorology \\
\hline Honolulu, Hawaii & June $2-11$ & International Conference on Tropical Meteorology, cosponsored by WMO \\
\hline Boulder, Colo. & June 15-18 & Symposium on the Dynamics of the Mesosphere and Lower Thermosphere \\
\hline
\end{tabular}

\section{Conference on the Global Circulation of the Atmosphere}

to be held in London, 25-29 August 1969 by the Royal Meteorological Society and the American Meteorological Society in collaboration with the Royal Society and with the participation of the Canadian Meteorological Society

\section{OUTLINE PROGRAMME}

Monday, 25 August 1969

Session I Morning The nature of the global circulation of the atmosphere.

Session 2 Afternoon Numerical simulation of the global atmosphere.

Evening Reception by the Host Country. 
Tuesday, 26 August 1969

Session 3 Morning Energy balance of the global atmosphere.

Session 4 Afternoon Boundary layer transfer processes.

Evening Reception by the American Meteorological Society.

Wednesday, 27 August 1969

Session 5 Morning Tropical circulation and convective processes.

Afternoon Excursion by coach to the Headquarters of the Meteorological Office.

\section{Thursday, 28 August 1969}

Session 6 Morning The role of extra tropical disturb. ances in the global atmosphere.

Session 7 Afternoon The structure and dynamics of the lower stratosphere.

Friday, 29 August 1969

Session 8 Morning a. The scope and application of laboratory models of the atmosphere.

b. Recent developments in satellite techniques for observing and sensing the atmosphere.

Session 9 Afternoon Progress report on the planning and implementation of GARP and World Weather Watch.

Evening Subscription Banquet.

\section{ADVANCE INFORMATION}

1. The Conference will be held in the Rooms of the Royal Society in Central London.

2. It will be open to members and non-members of the Societies.

3. A Conference Registration Fee will be payable by all those attending the sessions. This must be remitted with the Conference Reservation Form (see paragraph 6 below).

4. The Registration Fee will entitle visitors to attend the sessions, the social events (accompanied where applicable by their ladies), and to a copy of the Proceedings which will be published subsequently as a hard-back volume containing the contributions of the main speakers. Additional charges will be made for the Excursion and the Subscription Banquet.

5. Visitors will be responsible for making their own reservations for accommodation. These can be effected through any office of Messrs. Thomas Cook \& Son Ltd., Dean and Dawson Ltd., or Wagons-Lits/Cook, who have been advised of the Conference. Prompt application is recommended.

6. The full Programme and Conference Reservation Forms will be circulated with the April issue of the Quarterly Journal and the May issue of 'Weather.'

The program was published in the May Bulletin.

\section{Travel funds}

The American Meteorological Society expects to have limited travel funds to cover the travel (Boston-London economy round trip group fare only) of a small number of United States non-governmental scientists to the Royal Meteorolological Society-American Meteorological Society Conference on the Global Circulation of the Atmosphere to be held in London, 25-29 August 1969. Request for application should be addressed to the Executive Director, American Meteorological Society.

\section{Group travel}

Group travel can be arranged from Boston to London leaving Saturday, 16 August, and returning Monday, 1 September, if there is sufficient interest. Further information will be forwarded as to exact fares, times, deposits, etc., as soon as they can be determined. Estimated affinity fare, Boston-London round trip, 50 persons or more, $\$ 238$ per person; $25-50$ persons, $\$ 293$ per person. Those members and families interested in taking advantage of reduced group travel rates should indicate, at least a tentative interest to the Executive Director, American Meteorological Society, as soon as possible.

\section{Third Conference on Weather Forecasting and Analysis, September 3-5, 1969, Virginia Beach, Va.}

The Hampton Roads Chapter located in the Norfolk area of Virginia announces that the 3rd Conference on Weather Forecasting and Analysis, sponsored by the American Meteorological Society will be held at the Cavalier Hotel, Virginia Beach, Va., September 3-5, 1969.

Papers will deal with all facets of weather forecasting and analysis. The program will be published in the June 1969 Bulletin. Dr. E. C. Kindle is Program Chairman, Navy Weather Research Facility, Bldg. R-48, Naval Air Station, Norfolk, Va. 23511.

The program appears on page 449 .

\section{9th Conference on Agricultural Meteorology, September 8-10, 1969, Seattle, Wash.}

The Ninth Conference on Agricultural Meteorology of the American Meteorological Society will be held on the University of Washington campus at Seattle, Wash., September 8-10, 1969.

The local arrangements chairman is Dr. Leo J. Fritschen, Collcge of Forest Resources, University of Washington, Seattle, Wash. 98105.

Program chairman is Dr. R. J. Hanks, Department of Soils and Meteorology, Utah State University, Logan, Utah 84321.

The program appears on page 463 .

\section{Conference on Plan for U. S. Participation in the Global Atmospheric Research Program, October 15-17, 1969, Boulder, Colo.}

Plans for U. S. participation in the Global Atmospheric Research Program (GARP), as developed by the U. S. Committee for GARP of the National Academy of Sciences-National 
Research Council, and related scientific and technological subjects will be presented and discussed by Committee representatives and invited speakers. The meeting is planned mainly for the information of atmospheric researchers especially those interested in participating in various aspects of GARP. Sponsors include the American Geophysical Union, the American Meteorological Society, and the University Corporation for Atmospheric Research. The National Center for Atmospheric Research in Boulder will serve as host.

Dr. Richard J. Reed, National Academy of Sciences-National Research Council, is Program Chairman. John E. Masterson, NCAR, is in charge of arrangements.

Due to limitations on accommodations in Boulder, advance registration will be required. Additional information on the program, travel and hotel arrangements, etc., will be given in forthcoming issues of the AMS Bulletin and AGU Trans. actions.

Those wishing additional information may write John E. Masterson, NCAR, Post Office Box 1470, Boulder, Colorado 80302.

\section{ASCE's Sixth National Meeting on Environmental Engineering, October 13-17, 1969, Chicago, III.}

The American Society of Civil Engineers' Sixth National Meeting on Environmental Engineering will be held at the Pick-Congress Hotel, October 13-17, 1969, in Chicago, Ill. The American Meteorological Society is a cooperating organization. The Technical Program Chairman is Paul $\mathbf{H}$. Kaar, Portland Cement Association, 5420 Old Orchard Rd., Skokie, Ill. 60076. Further information may be obtained from ASCE, 345 East Forty-Seventh St., New York, N. Y. 10017.

A session of particular interest on Accidental and Planned Weather Modification is tentatively scheduled for Wednesday afternoon. The moderator is $\mathbf{F}$. Laverty and the session will include the following papers: Atmospheric Pollution and Weather Modification by V. J. Schaefer, Increased Precipitation from Urban Industrial Effects by S. Changnon, The Silver Iodide Generator and Public Health by W. Douglas, and Planned Weather Modification by R. A. Schleusener.

First Symposium on Atmospheric Sciences Education, scheduled for October 14-16, 1969, Urbana, III., has been postponed indefinitely.

\section{The Sixth International Symposium on \\ Remote Sensing of Environment, October 14-16, 1969, Ann Arbor, Mich.}

The Sixth International Symposium on Remote Sensing of Environment will be held October 14-16, 1969, on the campus of the University of Michigan. The symposium will be conducted by The Center for Remote Sensing Information and Analysis.

The purposes are the presentation of reports on work in progress in the field of remote sensing and the stimulation of an exchange of information concerning the numerous aspects of the field with emphasis on data acquisition, interpretation, and handling techniques. Contributed papers will make up the bulk of the program. In addition, there will be invited papers treating specific topics, particularly in geography, meteorology, and oceanography. Panel sessions will be arranged to discuss the impact of remote sensing upon society and the lessons learned in planning and conducting remote sensing experiments (failures as well as successes). The symposium will be of interest to people working on the exploitation and conservation of natural resources, on investigations of the quality of man's environment, and in the various engineering fields and areas of sensor technology. The symposium is an unclassified forum and open to all who have an interest in remote sensing.

For further details concerning program and registration information, kindly contact: Extension Service, Conference Department, The University of Michigan, Ann Arbor, Michigan 48104 (area code 313-764-5304).

\section{Call for Papers}

\section{Symposium on "The Future of the Atmosphere," Oct. 21-22, 1969, Madison, Wis.}

The American Meteorological Society will sponsor a Symposium on "The Future of the Atmosphere," Oct. 21-22, 1969, at the new Meteorology and Space Science Building on the Madison campus of the University of Wisconsin. This meeting is in conjunction with dedication ceremonies for the Meteorology and Space Science Building.

The subject of the symposium is oriented not only in the spirit of a building dedication but also toward the dedication of atmospheric science to meet the problems of the future. Four sessions are planned: 1) Looking Back, 2) The Present Atmosphere, 3) The Future of the Atmosphere and 4) The Future of Atmospheric Sciences. The first session deals with the history of the atmosphere both in terms of its origin and past climatic conditions. The second emphasizes the present state of our observational theoretical knowledge of the atmosphere. The third brings forth future problems such as pollution and weather modification. The last session focuses on the central issues of the future of the profession: The scientific and technical manpower needs and the development of programs and organizations to make the best use of this manpower.

Invited papers are planned for each session. Contributed papers of general interest are also solicited. Abstracts and titles should be sent before 1 June 1969 to the Program Chairman, Prof. Reid Bryson, Department of Meteorology, Univ. of Wisconsin, Madison, Wis. 53706. This meeting was originally scheduled for May.

\section{Fifth Annual American Water Resources Conference, Oct. 27-31, 1969, San Antonio, Tex.}

The Fifth (Annual) American Water Resources Conference will be held in conjunction with the 15th Annual Water for Texas Conference to be held at the El Tropicano Motor Hotel, San Antonio, Tex. The general conference theme is "Water for the United States." The technical program chairman is Dr. William B. Davis, Environmental Engineering Division, Texas A\&M University, College Station, Texas 77843.

\section{Call for Papers}

Third Conference on Weathercasting, November 7 and 8, 1969, Chicago, III.

A national conference on radio and television weathercasting, sponsored by the American Meteorological Society, will be 
held at the Executive House in Chicago, Illinois, on Novem. ber 7 and 8, 1969. The current committee on Radio and Television Weathercasting will serve as the program committee.

The purpose of the conference is to bring together meteorologists who are actively participating in broadcasting media, or whose interests are closely associated with such media. Both professionals and non-professionals are invited to attend.

Papers will be welcomed on any and all subjects of weathercasting such as: broadcast formats and techniques, the AMS Seal of Approval program, the role of the non-professional, instrumentation, management-weathercaster relations. Also invited are papers dealing with the career aspects of weathercasting and formal preparation for such a career.

Specialized sessions will be organized, depending upon the nature of papers submitted for presentation.

Titles, abstracts, projection requirements, and presentation time should be submitted by June 15, 1969, to the Program Chairman: Gordon Weir, KNBC News, 3000 West Alameda Avenue, Burbank, Calif. 91503.

\section{Call for Papers}

\section{Sixth Technical Conference on Hurricanes, December 2-4, 1969, Miami Beach, Fla.}

The Sixth Technical Conference on Hurricanes, jointly sponsored by the American Meteorological Society and its Greater Miami Chapter, will be held at the Americana Hotel, Bal Harbour, Miami Beach, Fla., December 2-4, 1969. The Sixth Conference scheduled for Hawaii has been rescheduled to Miami, and the Hawaii meeting in June 1970 will be oriented very broadly around tropical meteorology.

The Conference will deal with all phases of tropical cyclones as well as related meteorological topics. The topics of the individual technical sessions will be determined by the content of the papers to be presented. Invited papers from a number of recognized experts will be solicited. These will be supplemented by volunteered contributions. However, in order to allow for adequate discussions, some volunteered papers may be selected to be read by title only.

Those wishing to present papers should send titles, comprehensive abstracts, times required for presentation and projection requirements to the program chairman, Dr. Stanley L. Rosenthal, National Hurricane Research Laboratory, P. O. Box 8265, University of Miami Branch, Coral Gables, Florida (33124). Abstracts must be received prior to 1 August 1969. It is recommended that authors submit only one paper.

\section{IUGG-IAMAP-AMS Conference on Planetary Boundary Layer, March 18-21, 1970, Boulder, Colo.}

This meeting will be devoted to discussions of current research related to the integration of mechanisms describing boundary layer processes into models of larger scale atmospheric and sea motion. Emphasis will be placed on the fundamental aspects of recent developments in experimental and theoretical methods of boundary layer studies as they bear on the principal objective. To take account of different approaches to examining boundary layer dynamics, it is hoped that this meeting will bring together groups of theoretical fluid dynamicists, meteorologists, oceanographers, and laboratory experimentalists for extensive formal and informal discussions. The program will be organized broadly along the following topics: Part I-Assimilation of Boundary Layer Dynamics into Models of Large Scale Motion, A. The Earth's Atmosphere, B. Ocean Circulation; Part II-Dynamics of the Surface Laver, A. Turbulent Flow Over Land with Roughness of Heights Less Than $10 \mathrm{~m}$, B. Turbulent Flow Over Land with Roughness of Heights Greater Than 10 m, C. AirSea Interaction, D. Buoyant Convection; Part III-Dynamics of Intermediate Scale Motions, A. Boundary Layers in Rotating Systems, B. Orographic Effects, C. Meso-Scale and Larger Land and Sea Effects.

Invited papers will be solicited by various chairmen for each session. These presentations will be rather comprehensive in nature, leading into extensive informal discussions on new research topics. Contributions will be scheduled, if possible, during periods set aside for the informal discussions.

For further information, please contact G. M. Hidy, Science Center, North American Rockwell Corporation, 1049 Camino dos Rios, Thousand Oaks, California 91360.

\section{Conference on the Motion and Dynamics of the Atmosphere, March 23-25, 1970, Houston, Tex.}

Workers with theoretical developments in atmospheric dynamics and with mathematical models of atmospheric motions on any scales (planetary, macro-, synoptic, meso-, and micro-) are invited to submit papers. It is planned to give each author time for a full development of his work including assumptions, pertinent mathematical tricks and conclusions. It is assumed that the discussion will be critical. Titles and abstracts (or outlines) should be sent to Joseph $\mathbf{L}$. Goldman or John C. Freeman, Jr., Institute for Storm Research, 3812 Montrose Blvd., Houston, Texas 77006 by 15 October 1969.

\section{Call for Papers}

\section{Second National Conference on Weather Modification, Santa Barbara, Calif., April 6-9, 1970}

The Second National Conference on Weather Modification will be held in Santa Barbara, Calif., April 6-9, 1970. The program will be oriented toward the applied science and engineering aspects of weather modification.

It is planned to conduct sessions under the following general headings:

1) Inadvertent weather modification.

2) Orographic cloud seeding.

3) Cloud seeding numerical models.

4) Fog modification.

5) Hail suppression and warm cloud seeding.

6) Weather modification instrumentation.

7) Climatic change.

8) Social, legal, and economic aspects of weather modification.

Titles and abstracts of 200 to 300 words must be submitted to the program chairman by October 20,1969 . A set of preprints will be published and authors must be prepared to submit full copies of their papers in article form by January 20, 1970.

Titles, abstracts, projection requirements, and requested presentation time should be sent by 20 October 1969 to Program Chairman, Robert D. Elliott, North American Weather Consultants, Santa Barbara Municipal Airport, Goleta, Calif. 93017. 


\section{Call for Papers}

\section{Fourth Conference on Aerospace Meteorology, May 4-7, 1970, Las Vegas, Nev.}

The Fourth National Conference on Aerospace Meteorology is being arranged by the AMS Committee on Atmospheric Problems of Aerospace Vehicles aided by the AIAA Committee on Atmospheric Environment. The Institute of Environmental Sciences will be responsible for a session on testing in simulated natural environments.

\section{Theme}

The theme of this meeting is meteorology in design, test, and operation of current and future aerospace vehicles including balloons, aircraft of all types, rockets, missiles, space vehicles, and satellites. Papers being sought fall into two major categories:

a. Meteorological studies related to aerospace system design and operational problems.

b. Engineering studies of the influence of meteorological parameters in mission planning, design, test, and operation of aerospace systems.

\section{Topics}

Problem areas of particular interest include:

1. Special meteorological problems encountered on aerospace vehicles test ranges.

2. Mesoscale pressure, temperature, atmospheric motion, and other gradients important in SST design and operation.

3. Meteorological problems of aerodynamic lift, hypersonic speed aerospace vehicles.

4. Artificial satellite meteorological problems, especially those related to portions of orbital flights within the sensible atmosphere.

5. Meteorological problems related to design and operation of advanced ballooning systems.

6. Atmospheric models for aerospace vehicle design and operation.

7. Wind and turbulence problems during launch and powered flight of rockets, missiles, and space vehicles.

8. Meteorological problems related to impact or recovery of re-entry vehicles.

9. Meteorological instrumentation design for test range operational support of aerospace systems.

10. Special studies of clouds, water vapor, ozone, other aerosols and constituents for specific aerospace system problems.

11. Development of meteorological design standards and tests for aerospace vehicle development.

12. Testing of aerospace vehicles concepts in simulated atmospheric environments.

13. Aerospace problems in the atmospheres of other planets.

14. Other meteorological aerospace vehicles design, test, and operation problems not heretofore listed.

\section{Abstracts and papers}

Abstracts of papers must be submitted by 1 September 1969 but should be submitted as early as possible in order to permit adequate consideration by the program committee. Abstracts must be between 200 and 400 words long. Complete camera-ready copy of accepted papers, not to exceed 10 single spaced pages (including abstract and illustrations), must be received by 15 December 1969 in order to be included in this conference.

\section{Proceedings}

All papers will be published in Proceedings and will be provided to preregistrants one month in advance of the meeting. Other attendees will receive Proceedings when registering. Tentative plans, contingent upon review of papers selected, is that there will be no formal presentation of papers at this meeting. Should these tentative plans appear workable, the morning of registration day, as well as the preregistration period, will be allotted for individual study of the Proceedings.

\section{Meeting format}

Authors of papers accepted will be divided into panels according to topic areas. Panelists must meet with their chairman during workshop sessions to be conducted on the afternoon of registration day. Other attendees may attend any workshop. During each workshop session panels will develop material for a general session. About ten workshops and general sessions are anticipated.

General sessions, commencing on the second day and continuing for 2 to 3 days, will start with a short overview by the session chairman and be followed by very short informal talks by each author. These will describe, only in general, details of the study but will emphasize findings. Showing of many slides in these informal talks should be avoided, but showing of 1 or 2 summary type slides, not necessarily in the formal paper, is encouraged. Presenting summary material in a chalk talk is also encouraged. Following introductory material by chairman and panelists, sessions will be open to informal discussion between panelists and between the panel and attendees. Total time for each general session will be about 1-1/2 hours. Time for audience participation will equal or exceed that allotted to chairmen and panelists for introductory material. Half hour coffee breaks between sessions are planned to permit extension of discussion into these breaks, should there be sufficient interest.

The format described above is an cxperimental attempt to avoid exposing attendees to unimportant details which cannot be easily followed, to avoid double sessions, to enliven sessions, and bring out the important findings by face to face discussions. Considerable work will be required of the session chairman. If, in general, the papers submitted do not lend themselves to this format, the meeting will revert to the usual presentation of individual papers. If the experimental format is decided upon but some pertinent papers do not fit into the panel format, there may be a limited number of individual presentations. Potential attendees are invited to forward suggestions concerning this tentative format to the Program Chairman.

\section{Submission of papers}

Abstracts of meteorological studies, category a, should be submitted to Program Chairman, Norman Sissenwine, AFCRL (CREW), L. G. Hanscom Field, Bedford, Mass. 01730. Abstracts of engineering studies, category $b$, should be submitted to co-Chairman, Wm. W. Vaughan, NASAMarshall Space Flight Center, Code: R-AERO-Y, Huntsville, Alabama 35812. Invitations to submit completed papers will be based upon the pertinence of the abstract to the theme of the meeting and, so, abstracts should provide some indication of the findings. 


\section{Call for Papers}

Symposium on Tropical Meteorology,

June 2-11, 1970, Honolulu, Hawaii

The American Meteorological Society's Symposium on Tropical Meteorology, cosponsored by the World Meteorological Organization will be held at the University of Hawaii, Honolulu, Hawaii, on June 2-11, 1970.

The Symposium will include invited papers and panel discussions. Papers are solicited on tropical meteorology topics with the exception of tropical cyclones. The tropical continents will be featured.

Program details will appear in later issues of the BulleTiN. Address inquiries to: Elmer M. Chadsey, 1350 Ala Moana Blvd., Apt. 2504, Honolulu, Hawaii 96814.

\section{Call for Papers}

Symposium on the Dynamics of the Mesosphere and Lower Thermosphere, June 15-18, 1970, Boulder, Colo.

A special symposium of the American Meteorological Society on "The Dynamics of the Mesosphere and Lower Thermosphere," will be held on the University of Colorado campus at Boulder, Colo., on June 15-18, 1970.
Contributed papers (approximately 15 minutes each) covering the following general subject areas, as applied to the middle atmosphere $(30-100 \mathrm{~km})$ will be welcomed:

1) Radiative processes and the distribution of radiative sources and sinks

2) Composition and photochemistry

3) Observations and theoretical models of the general circulation

4) Motions on different scales-such as: gravity waves, synoptic and Rossby-Haurwitz (planetary) waves, tidal oscillations

5) Energetics of atmospheric motions

6) Phenomena involving interactions between different atmospheric regions

7) Interaction of dynamics and composition (including transport processes)

Invited review papers are planned for each topic to be discussed.

Titles and informative abstracts (up to 400 words) of all contributed papers must be submitted before March 15, 1970, for review towards inclusion in the program. All abstracts and inquiries should be directed to the program chairman, Prof. Julius London, Department of Astro-Geophysics, University of Colorado, Boulder, Colorado 80302.

\section{PROCEEDINGS OF THE THIRD CONFERENCE ON AEROSPACE METEOROLOGY}

Through a cooperative effort of the American Meteorological Society, the American Institute of Aeronautics and Astronautics and the Institute of Environmental Sciences, the Third Conference on Aerospace Meteorology was held from May 6-9, 1968 in New Orleans, La. This interdisciplinary conference afforded an opportunity for engineers to present their analyses of interactions of the atmosphere with aerospace systems, and for meteorologists to present advancements in their understanding and description of the atmosphere, to aerospace design engineers and operational personnel.

The Proceedings represent papers in the following areas:

$$
\begin{gathered}
\text { Environment Considerations in Aerospace Program } \\
\text { Sensing the Aerospace Environment } \\
\text { Wind Profiles-Measurement Systems and Studies } \\
\text { Low Level Winds and Wind Measurement Studies } \\
\text { Atmospheric Modeling and Spacecraft Interactions } \\
\text { Wind Profiles-Aerospace Vehicle Applications } \\
\text { Simulation Problems and the Aerospace Environment } \\
\text { Problems of Seeing Through the Atmosphere and Sound Propagation } \\
\text { Upper Atmosphere (30km) Variability } \\
\text { Aircraft Environment Interactions and Atmospheric Turbulence }
\end{gathered}
$$

Price: $\$ 20$ nonmembers

580 pages

$\$ 15$ AMS members

SEND ORDERS TO: $\quad$ AMERICAN METEOROLOGICAL SOCIETY, 45 Beacon St., Boston, Mass. 02108 